\title{
The Biography of Specimen "09.04.1954, 3.4 mm” from the "Blechschmidt Collection of Human Embryos" at Göttingen University with a Special Focus on the Production and Usage of Enlarged 3D Replicas of Embryos in the Anatomical Research on Human Embryos
}

\author{
Jörg Männer ${ }^{\mathrm{a}}$ Michael Markert $^{\mathrm{b}}$ \\ anstitute of Anatomy and Embryology, UMG, Georg-August-University of Göttingen, Göttingen, Germany; \\ bProfessur für Materialität des Wissens, Kunstgeschichtliches Seminar, Georg-August-University of Göttingen, \\ Göttingen, Germany
}

\section{Keywords}

History of human embryology · Erich Blechschmidt · Human embryo collections $\cdot$ Specimen biography $\cdot$ Modelling

\begin{abstract}
The "Blechschmidt Collection of Human Embryos" housed at the Anatomical Institute of Göttingen University (Germany) is an important historical collection of human embryo specimens whose history dates back up to the mid-1940s. It is named after its founder Prof. Erich Blechschmidt (19041992). A 2-year research project was conducted from 2017 to 2019 with the aim of clarifying the provenience of the human embryo specimens collected by Blechschmidt. This project not only has provided information on the origin of the specimens but, additionally, led to the discovery of photographic documents illustrating the process by which Blechschmidt built the enlarged 3-dimensional replicas of human embryos that are shown in a dedicated exhibition hall in the basement of the Anatomical Institute. Here, we report on an embryo from the Blechschmidt collection whose biography as a microscopical specimen as well as a source for objects of Blechschmidt's collection of 3-dimensional replicas of human embryos is documented by letters,
\end{abstract}

karger@karger.com www.karger.com/cto

Karger $\stackrel{\text { '⿳亠丷厂 }}{ }$ GOPEN ACCESS
(C) 2021 The Author(s)

Published by S. Karger AG, Basel

This article is licensed under the Creative Commons Attribution 4.0 International License (CC BY) (http://www.karger.com/Services/ OpenAccessLicense). Usage, derivative works and distribution are permitted provided that proper credit is given to the author and the original publisher. lab-books, and photographs. Our report is complemented by a short historical review on the production and usage of enlarged 3-dimensional replicas in research on the anatomy of human embryo.

(C) 2021 The Author(s)

Published by S. Karger AG, Basel

\section{Introduction}

The "Blechschmidt Collection of Human Embryos" housed at the Anatomical Institute of Göttingen University in Germany is a unique historical collection of human embryo specimens whose history dates back up to the early 1940s [Markert, 2020]. The collection is named after its founder Prof. Erich Blechschmidt (*1904-1992†], who was the director of the Anatomical Institute from 1942 to 1973 [Hinrichsen, 1992]. It consists of 2 subcollections: first, a collection of 430 sets of serial histological sections of complete human embryos and fetuses or parts/organs of human embryos and fetuses (totally more than 200,000 sections mounted on more than 20,000 glass slides) and, second, a collection of 61 large-scale 3-dimensional (3D) replicas and models of human embryos (about $75 \mathrm{~cm}$ high) and fetuses. Most of the latter objects were con-
Correspondence to:

Jörg Männer, jmaenne@gwdg.de 
structed from 2-dimensional histological datasets by a modification of the wax plate reconstruction method [Blechschmidt, 1954], originally invented by Gustav Born, the father of the Nobel laureate Max Born [Born, 1876, 1883; Born et al., 1950].

The Blechschmidt collection of 3D replicas of human embryos documents, at a macroscopically visible scale, the dynamically changing external and internal anatomy of human beings during the first 8 weeks of prenatal life (postmenstrual weeks 3-10). The first week of prenatal development is documented by hand-made models of a 2-cell-stage egg and a blastula that were made based on microphotographs published in the literature. The second and third embryonic weeks are documented by 6 replicas of human embryo specimens from collections outside Germany (No. 5960, 7802, and 8171 from the Carnegie Collection, Washington D.C., USA; embryo "Ludwig" from the Anatomical Institute in Basel, Swiss), while the fourth to eight embryonic weeks are documented by 40 replicas of 9 specimens from Blechschmidt's own collection. Special aspects, such as the development of the face, skull, inner ear, etc., are documented by 13 replicas. The replicas are shown in a dedicated exhibition hall, which is open to the public. The study of the whole collection of 61 replicas provides a kind of 4-dimensional image of early human development. This image, composed of 61 "snapshots" of embryonic morphogenesis, may be compared with the picture provided by a complete jigsaw puzzle. According to this analogy, each single embryo replica may be seen as representing only one piece of a complex jigsaw puzzle, which, in its entirety, acts as a single model for early human morphogenesis [Männer, 2014].

As described in a preceding paper published in this journal [Markert, 2020], a 2-year research project was conducted from 2017 to 2019 with the aim of clarifying the provenience of the historical human embryo specimens housed in the "Blechschmidt Collection of Human Embryos." This project not only has provided information on specimen acquisition and ethical issues of the collection but, additionally, led to the discovery of photographic documents illustrating the process by which Blechschmidt and his staff built the enlarged 3D replicas of human embryos that make up the pieces of his complex jigsaw puzzle of early human morphogenesis. In this article, we report on an embryo from the Blechschmidt collection whose biography as a microscopical specimen as well as a source for pieces of Blechschmidt's jigsaw puzzle of early human morphogenesis is well-documented by letters, lab-books, and photographs. The documentation of the biography of this embryo is one of the most com- plete among the 9 specimens from Blechschmidt's collection used for the construction of 3D replicas.

The biography of this specimen not only discloses some historical aspects specific for Blechschmidt's institute. It also illustrates a more general aspect of the research on the anatomy of human embryos. This is the method of processing human embryo specimens that is most frequently used to visualize the external and internal anatomy of such very small biological objects. This method of embryo preparation consists of a sequence of operations that can be roughly subdivided into 2 partial processes. The first of these processes leads to the transformation of the embryo into a seamless series of histological sections. Histological sections facilitate the microscopic analyzes of its internal anatomy. However, they do not facilitate, the visualization of the $3 \mathrm{D}$ anatomy of the original specimen, which has been destroyed by the sectioning process. This problem is solved by the second partial process, which is the production of enlarged 3D replicas of the original specimen. Such replicas facilitate the macroscopic analysis of its complex 3D anatomy. The described sequence of embryo processing was already used by the Swiss anatomist Wilhelm His [Hopwood, 2002], the founder of human embryology [Müller and O'Rahilly, 1986]. It was later used in the Department of Embryology at the Carnegie Institution in Baltimore, MD, USA [Mall and Meyer, 1921] as well as in Blechschmidt's Anatomical Institute and in other institutions all over the world. It is, therefore, no wonder that institutions with a long history in research on the anatomy of human embryos typically harbor 2 different sets of historical embryo collections: (1) a collection of human embryo specimens that exists either in the form of chemically preserved intact specimens or as sets of serial histological sections, and (2) a collection of $3 \mathrm{D}$ replicas of the human embryo specimens. Blechschmidt's collection of 3D replicas of human embryos is unique in the world because it is open to the public and its replicas are 4- to 5-times larger than corresponding models from other collections.

Our report on the biography of an embryo from the Blechschmidt Collection follows the abovementioned sequence of specimen processing. It is, therefore, subdivided into 2 main parts describing (1) the origin of the specimen and its transformation into a seamless series of histological sections, and (2) the subsequent process of production of enlarged 3D replicas according to Blechschmidt's modification of Born's reconstruction method. Our descriptions are complemented by a short historical review on the production and usage of enlarged 3D replicas in research on the anatomy of human embryos. 
Fig. 1. a This historical microphotograph shows specimen "09-04-1954, $3.4 \mathrm{~mm}$ " before starting of the histological preparation. The specimen consisted of an opened chorionic sac harboring an intact human embryo (covered with amnion) of about 3 $\mathrm{mm}$ greatest length. $\mathbf{b}$ Microphotograph of the embryo after opening of the amniotic cavity. c, d Drawings depicting the outer shape of the embryo in left lateral view (c) and dorsal view $(\mathbf{d})$.
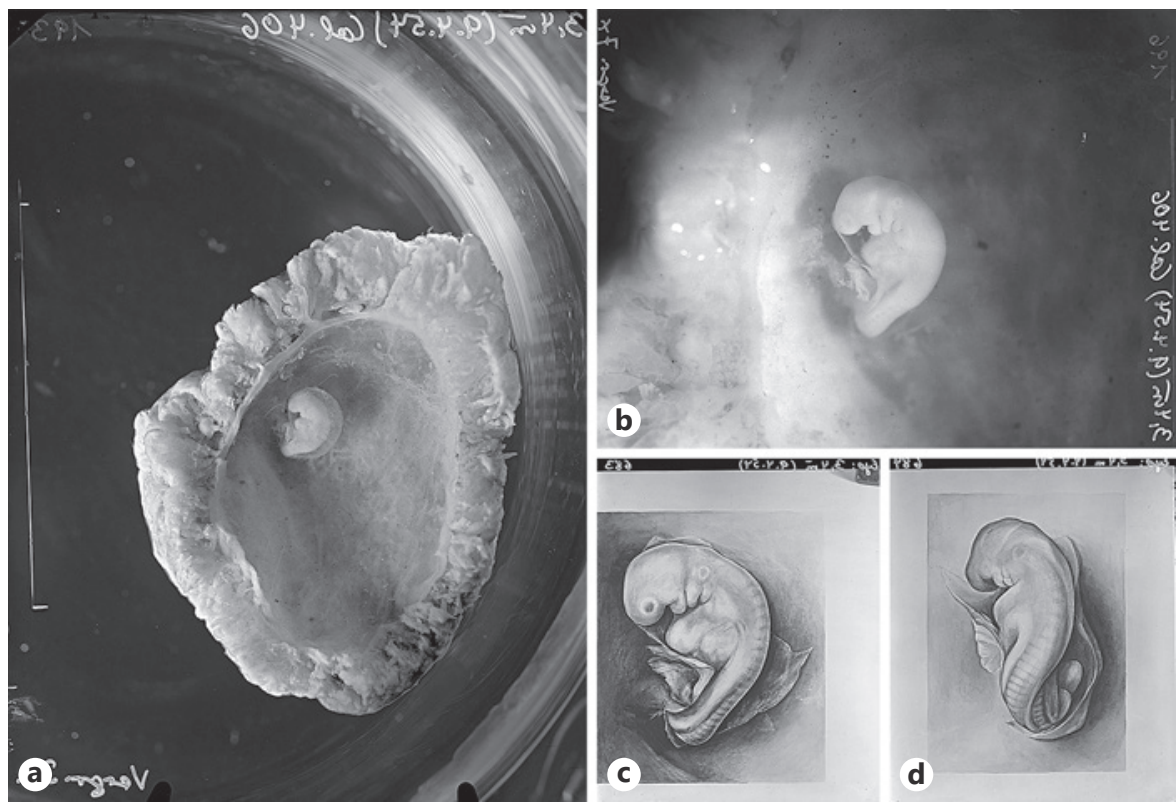

\section{Biography Part 1: Origin of the Embryo and its Transformation into a Histological Specimen Used for Biomedical Research}

The specimen chosen for presentation consisted of a chorionic sac harboring an intact human embryo of about $3 \mathrm{~mm}$ greatest length (Fig. 1). It was sent to Prof. Blechschmidt in a closed test tube with Bouin's solution (without acetic acid) on April 8, 1954. It arrived at the Göttingen Anatomical Institute on April 9, 1954, where it was immediately placed in a new test tube containing fresh Bouin's solution (with acidic acid). The sender of the specimen was head of a women's hospital in Hamburg, Germany. According to the accompanying letter, the specimen was obtained from a surgically removed uterus on April 7, 1954. The uterus was removed from the body of the mother by the "Wertheim operation", a surgical procedure named after the Austrian gynecologist Ernst Wertheim (*1864-1920†). The accompanying letter did not include any information about the menstrual age of the pregnancy. It also did not include any information about the age, reproductive history, medical diagnoses, or clinical history of the mother. However, the fact that the Wertheim operation is used to treat malignancies of the cervix uteri, uterus, and/or upper vagina, suggests that the mother of the embryo had suffered from a malignant gynecological tumor. The absence of any information about the menstrual age of the pregnancy may suggest that neither the mother nor the sender of the embryo may have noted the existence of the pregnancy before the Wertheim operation.

According to the embedding protocol No. 406 of Blechschmidt's lab (Fig. 2), the specimen was placed in fresh Bouin's solution at the Göttingen Anatomical Institute on April 9, 1954. This date, which marks the start of the histological preparation of the specimen, in combination with the greatest length of the embryo, measured under the dissection microscope before placing it in fresh Bouin's solution (with acidic acid), made up the object identifier that is in use up to now: "09-04-1954, 3.4 $\mathrm{mm}$." According to the length and morphological characteristics of the embryo (e.g., 27 pairs of somites), specimen "09-04-1954, $3.4 \mathrm{~mm}$ " nowadays would be classified as a Carnegie-stage 12 embryo [O'Rahilly and Müller, 1987].

Blechschmidt must have examined the intact embryo on the day of its arrival in Göttingen, since he sent a letter of thanks to the sender on April 10 (Fig. 3), stating that he was delighted about the embryo since he was looking for an embryo of the appropriate size for years. („Mit der Zusendung des "Wertheim" Embryo haben Sie mir eine besonders große Freude gemacht. Ich suche seit Jahren genau einen Embryo dieser Größe um endlich die Entwicklungsbewegungen des Zwerchfells in den kritischen Stadien untersuchen zu können ".). During his first examination of the fixed specimen, Blechschmidt removed the amnion and documented the outer shape of the embryo by microphotographs (Fig. 1b) and drawings (Fig. 1c, d). 
Fig. 2. Embedding protocol No. 406 of Blechschmidt's lab, which documents the transformation of specimen "09-04-1954, $3.4 \mathrm{~mm}$ " from a physically intact embryo embedded in its chorionic sac (April 9, 1954) into a seamless series of sagittal histological sections (May 29, 1954).

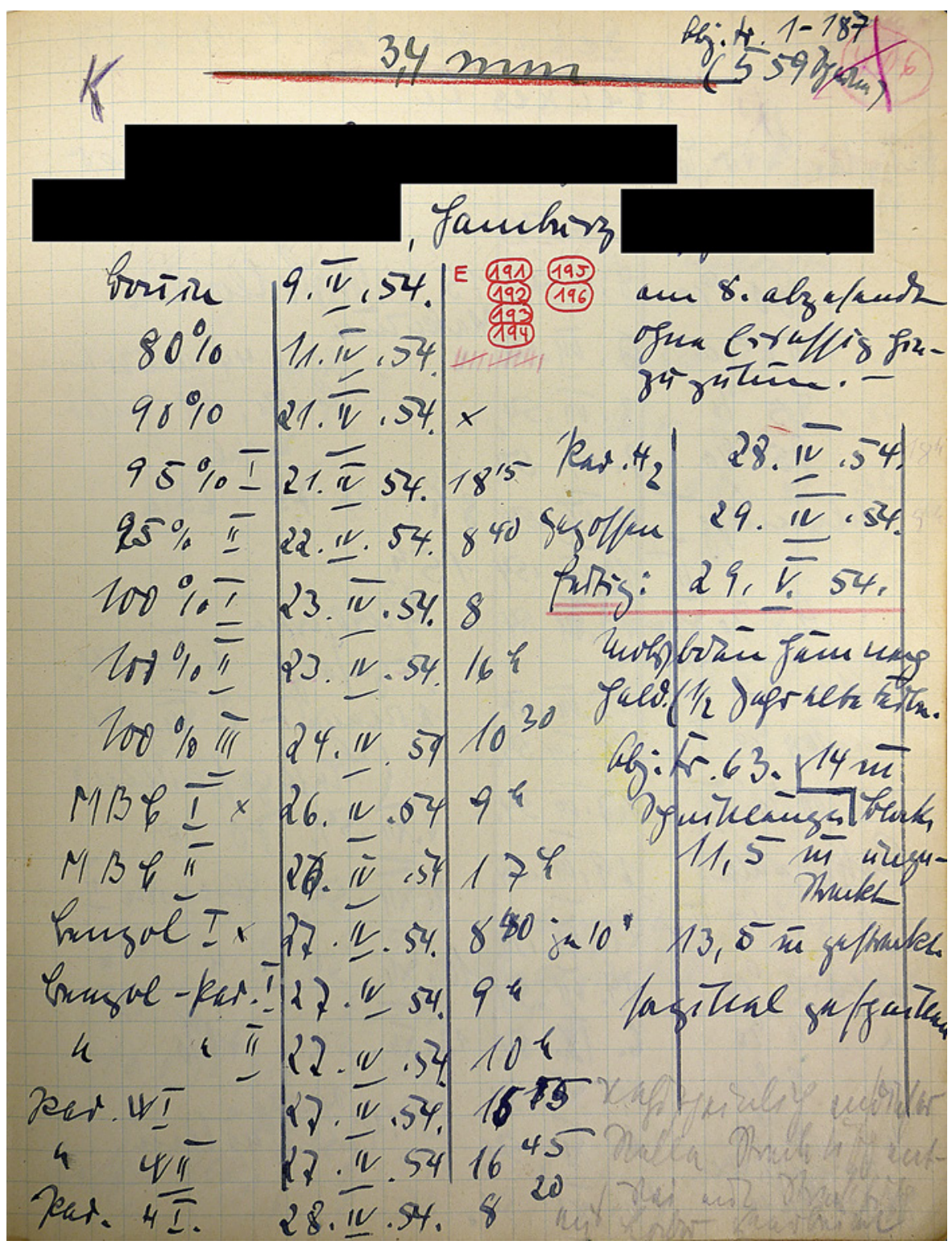

Within the following 7 weeks (from April 9, 1954 to May 29, 1954), specimen "09-04-1954, 3.4 mm" was transformed from a physically intact embryo embedded in its chorionic sac into a seamless series of sagittal histological sections suitable for light microscopical examinations and for the construction of enlarged 3D replicas of the embryo's body (section thickness: $10 \mu \mathrm{m}$, whole number of sections: 594 mounted on 187 glass slices, mounting medium: Rhenohistol, number of sections through the embryo: 189, section staining: Molybdenum-hematoxilin according to Held). Figure 4 shows 3 glass slides of this series.

\section{Biography Part 2: Integrating Embryo “09-04-1954, 3.4 mm" into Blechschmidt's Jigsaw Puzzle (model) of Early Human Morphogenesis}

The most important aim of Blechschmidt's work on human embryos was to document, at a macroscopically visible scale, the dynamic changes in the $3 \mathrm{D}$ anatomy of the human body during the first 8 weeks of prenatal life [Blechschmidt, 1954, 1955]. For this purpose, he built up his world-famous collection of enlarged replicas of human embryos, which, in its entirety, may be regarded as "the Blechschmidt model of early human morphogenesis" 


\section{0. $4 \cdot 1954$}

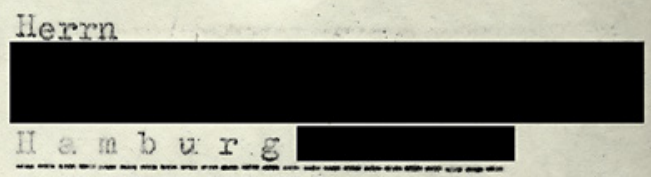

Sehr gechrter, Iieber Herr

Wit der Zusendung des "Wertheim" Bmbryo haben Sie mir eine ganz besonders grobe reude gemacht. Ich suche seit Jahren genau einen mbryo dieser Größe um endilch die nntwicklungsbevegungen des Zwerchfeils in den kritischen Stadien untexsuchen zu können. - Ich hoffe, deß nunmehr dic langgeplante Untersuchungen durcheluhrbar wird, obwohl beim ixieren leider vergessen wurde die boigegebene Itenge sisessig zuzuschiitten. Die Li.teraturangaben wären mir ohne dieses Bxenglar prektisch unzugänglich geblieben. Haben Sie deshalb sehr herzlichen Deak.

Lit frol. Grus

Ihr

Fig. 3. Blechschmidt's letter of thanks, which was sent to the sender of specimen "09-04-1954, $3.4 \mathrm{~mm}$ " on April 10, 1954.

(see above). According to the main aim of his work, Blechschmidt named this collection the "Humanembryologische Dokumentationssammlung Blechschmidt" (Blechschmidt collection for documenting human embryology). The replicas shown in this collection were used to produce many drawings published in Blechschmidt's books on human embryology.

In 1954, the year of the arrival of embryo "09-04-1954, $3.4 \mathrm{~mm}$ " in Göttingen, Blechschmidt's lab had a 12-year experience in the construction of large 3D replicas of human embryos. This learning phase of constructing large embryo replicas has just resulted in an institution-specific modification of Born's wax plate reconstruction method suitable for the construction of large replicas [Blechschmidt, 1954]. It is thus likely, that in this year, Blechschmidt already had started the building up of the replica collection as it is nowadays shown in the basement of the Anatomical Institute. Some pictures from the recently rediscovered archive of photographs from Blechschmidt's lab (see above) show objects from an obviously forgotten collection of enlarged human embryo models (Fig. 5a). The makeup of these objects is of a much lower quality than that found in today's collection of human embryo replicas (Fig. 5b). This suggests that they were made during Blechschmidt's 12-year-long (1942-1954) learning

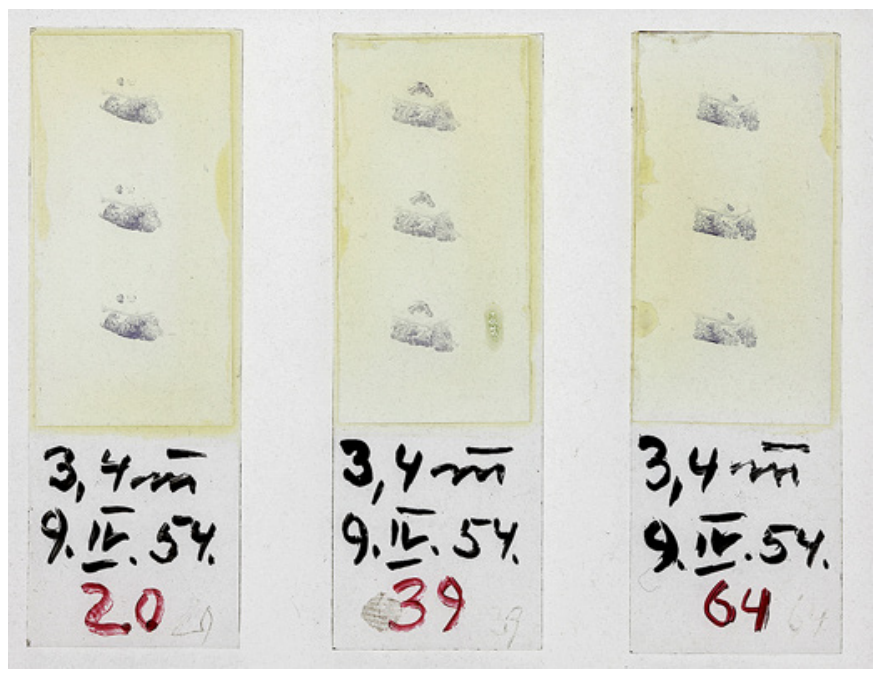

Fig. 4. This photograph depicts 3 glass slices from the whole series of 187 glass slices from specimen "09-04-1954, $3.4 \mathrm{~mm}$ ". These document the end point of the transformation process by which the originally intact embryo has become transformed into a histological specimen suitable for light microscopical examinations and for the construction of enlarged 3D replicas of the embryo's body. 

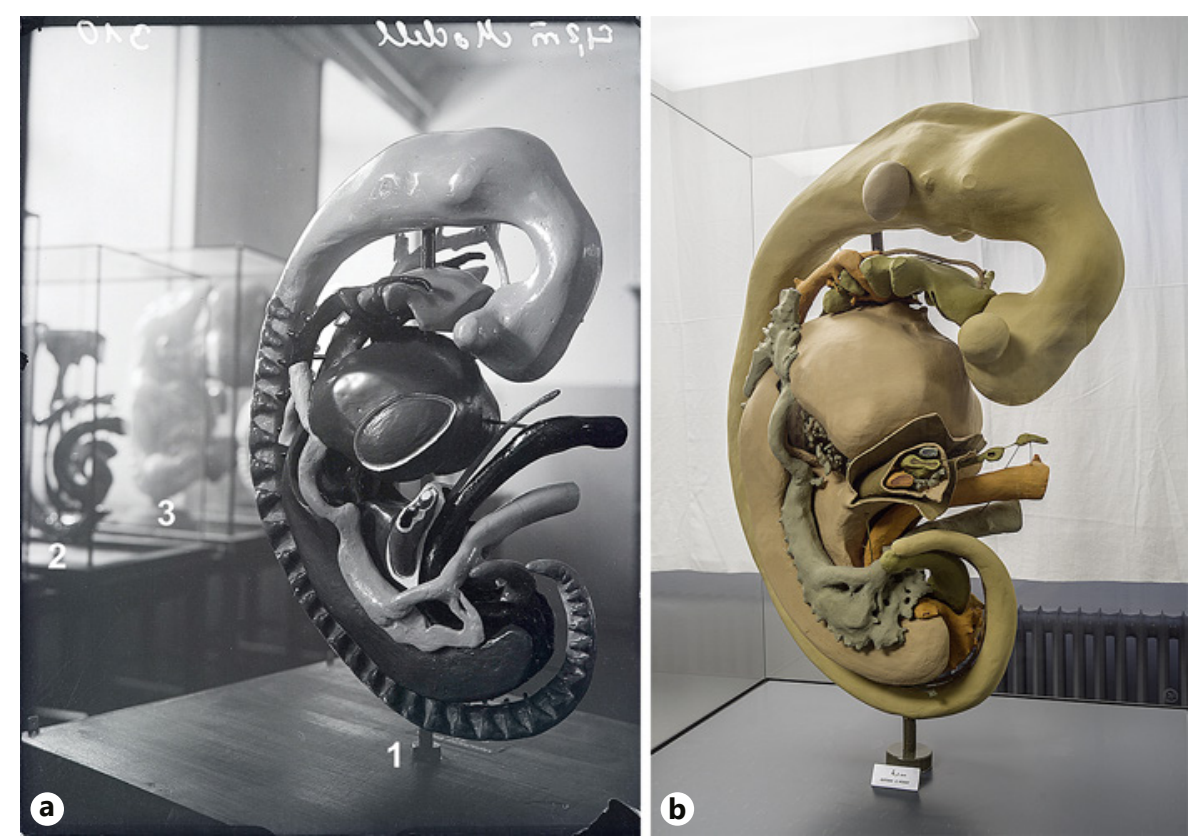

Fig. 5. a This historical picture, from the recently rediscovered photo archive of Blechschmidt's lab, shows 3 objects (1-3) from a collection of hitherto unknown human embryo models. The model shown in the front (1) depicts aspects of the internal anatomy of a $4.2 \mathrm{~mm}$ embryo from the Blechschmidt collection. This embryo arrived at Blechschmidt's lab in 1949 (object identifier "22-081949, $4.2 \mathrm{~mm}$ "). The "birthdate" of this model, therefore, must have been after 1949. The model in the background (3) depicts the outer shape of a $15 \mathrm{~mm}$ embryo, which arrived at Blechschmidt's lab in 1950 (object identifier "20-04-1950, $15 \mathrm{~mm}$ "; a photograph of this embryo is shown in the book "Die vorgeburtlichen Entwick-

process of constructing large embryo replicas. This idea may be supported by the fact that from this collection only a single object, depicting the historically $2.1 \mathrm{~mm}$ "Eternod" embryo [Eternod, 1896], has recently been rediscovered in the storage room of the Anatomical Institute. The fate of the rest of the "forgotten" Blechschmidt collection of human embryo models could not be clarified up to now. The fact that this collection contained models of human embryos that arrived in Blechschmidt's lab after 1945 (Fig. 5a) suggests that the "forgotten" Blechschmidt collection of human embryo models must have existed up to the 1950s. It is conceivable that most of these "learning objects" were discarded after the end of the "learning phase" of constructing large embryo replicas. Among Blechschmidt's publications, we have found only a single reference to this collection. This is a schematic line drawing of the abovementioned model of the $2.1 \mathrm{~mm}$ Eternod embryo. The figure was published on page 9 of Blechschmidt's 1944 monograph on the growth dynam- lungsstadien des Menschen/The stages of human development before birth." page 147, Fig. 96). b Replica of embryo "22-08-1949, $4.2 \mathrm{~mm}$ " found in today's collection of human embryo replicas. This replica depicts the same aspects of the internal anatomy as in the historical model shown in a. Compared to the historical replica, however, the model from the today's collection is of much higher quality. This suggests that the "birthdate" of the historical model must have been before 1954, when Blechschmidt published his modification of Born's wax plate reconstruction method [Blechschmidt, 1954].

ics of the tissues in the human body, where it was classified as "teaching model", $70 \mathrm{~cm}$ high, from the anatomical collection at Göttingen University [Blechschmidt, 1944].

The quality and morphological characteristics of specimen "09-04-1954, $3.4 \mathrm{~mm}$ " obviously made this embryo a suitable source for providing important pieces to Blechschmidt's jigsaw puzzle of early human morphogenesis. The today's replica collection harbors 3 enlarged replicas of this embryo, which show various aspects of its external and internal anatomy. The first replica (Fig. 6a1, a2) shows the external (ectodermal) shape of the embryo and the situs of the umbilical region; the second (Fig. 6b1, b2) focuses on the anatomy of the subdivisions of the coelomic cavity and their topographical relationships to the developing gut and neural tube; while the third replica (Fig. 6c1, c2) shows the complex morphology and topography of ectoderm-, mesoderm-, and endoderm-derived organs (nervous system, heart and blood vessels, mesonephros, primitive pharynx and gut). We do not know the 


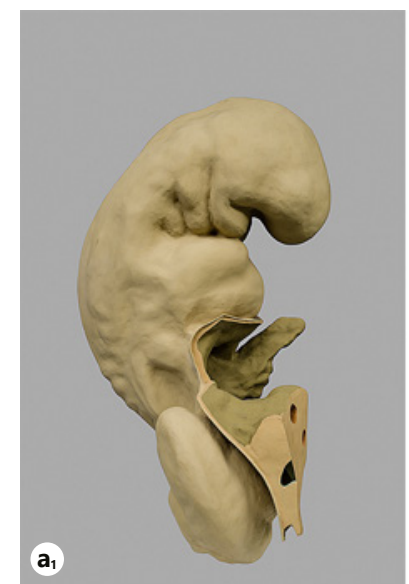

Fig. 6. a-c These photographs show the 3 replicas of embryo "09-04-1954, $3.4 \mathrm{~mm}$ " that are found in today's replica collection. The first replica (a1 = right lateral view, a2 $=$ left lateral view) shows the external shape of the embryo and the situs of the umbilical region. The second (b1, b2) focuses on the anatomy of the subdivisions of the coelomic cavity and their topographical relationships to the developing gut and neural tube. The third replica (c1, c2) shows the complex morphology and topography of ektoderm-, mesoderm-, and endodermderived organs (nervous system, heart and blood vessels, mesonephros, primitive pharynx and gut).

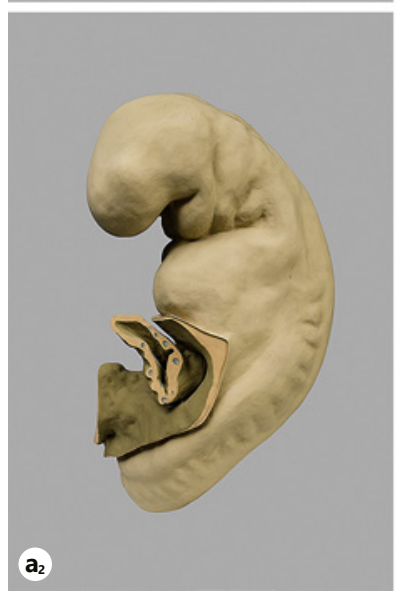

b
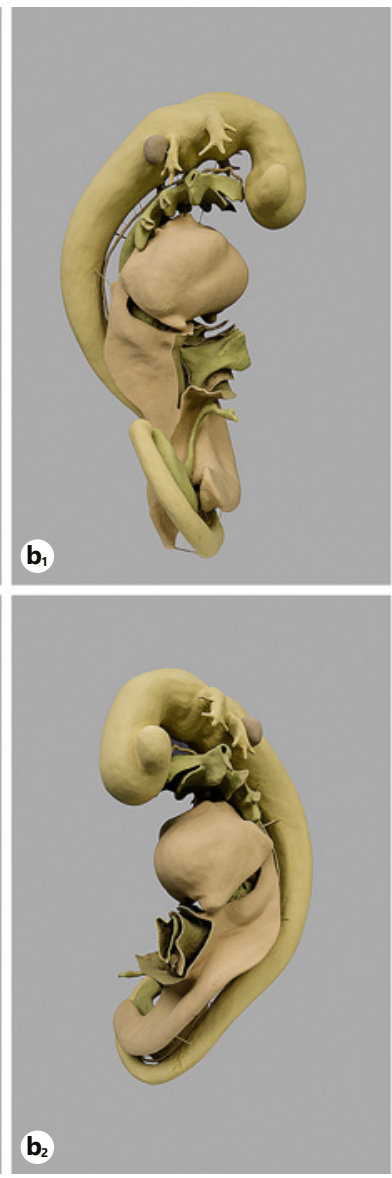

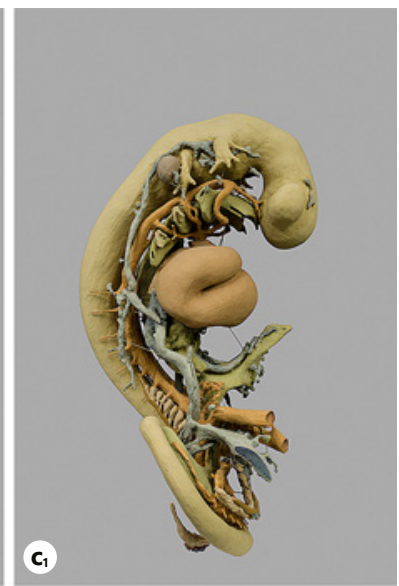

c

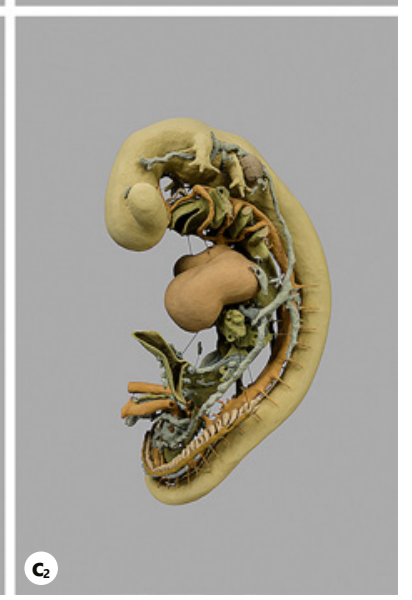

exact "birthdates" of these replicas. At least the first and second of them must have been finished before 1960 since they were published, for the first time, in Blechschmidt's 1960 monograph "Die vorgeburtlichen Entwicklungsstadien des Menschen" in the form of black and white drawings (see page 85, Fig. 60, 61). Pictures of the third replica appeared, for the first time, in Blechschmidt's "Der menschliche Embryo" from 1963, and therefore, this replica might have been built between 1960 and 1963 .

Blechschmidt has provided a detailed account of the technical aspects of his $3 \mathrm{D}$ reconstruction method in a paper published in 1954 [Blechschmidt, 1954]. This paper, unfortunately, did not provide any pictorial impressions of the "ontogenesis" of his large embryo replicas nor did it honor the people who were involved in the building up of his collection of enlarged human embryo replicas. The recently rediscovered archive of photographs from Blechschmidt's lab (see above) shed some light on the "ontogenesis" of the 3 replicas constructed from the histological data of embryo "09-04-1954, 3.4 mm." In the fol- lowing, we present a few pictures from this archive, which depict some steps in the ontogenesis of the abovementioned 3 replicas. To honor the people that made Blechschmidt's jigsaw puzzle of human embryogenesis real, we start with a photograph showing Wilhelm Kircheiss in his office (Fig. 7). This man was an engineer responsible for the realization of Blechschmidt's embryo reconstruction project during the 1950s and early 1960s. He also did most of the artwork published in Blechschmidt's books on human embryology. Wilhelm Kircheiss was hired for Blechschmidt's embryo reconstruction project in 1951, when this project received funding from the German Research Foundation (DFG). This means that Kircheiss joined Blechschmidt's Institute 3 years before Blechschmidt published his 1954 paper about his modification of Born's wax plate reconstruction method. In view of this fact, it is tempting to speculate that the abovementioned "forgotten collection of enlarged human embryo replicas" (Fig. 5a) may have been built up during the pre-Kircheiss era (1942-1951), while today's Blechschmidt col- 
Fig. 7. a This historical picture, from the recently rediscovered photo archive, shows $W$. Kircheiss in his office in the new building of the Anatomical Institute. W. Kircheiss was an engineer responsible for the realization of Blechschmidt's embryo reconstruction project. He also did most of the artwork published in Blechschmidt's books on human embryology (see the drawing of a $6.3 \mathrm{~mm}$ embryo on the desktop). b W. Kircheiss.
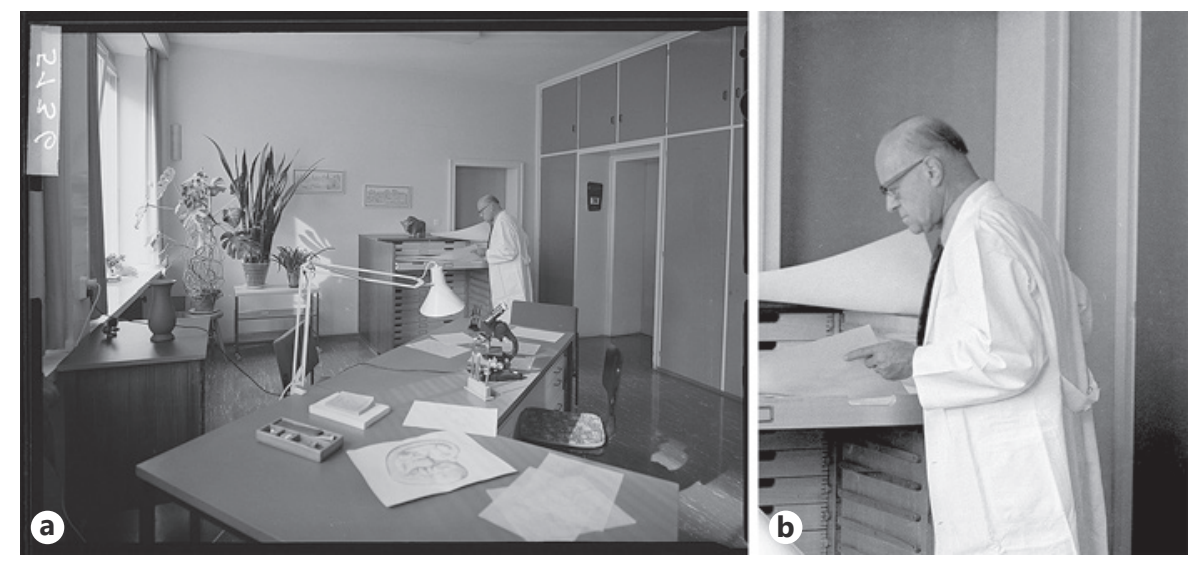

lection of human embryo replicas may be the product of the Kircheiss era. In view of his eminent contribution to Blechschmidt's scientific work, we wonder why Wilhelm Kircheiss did not receive much recognition of his work in the past. As far as we know, his work was honored only in a short note in the obituary for Erich Blechschmidt written by Klaus V. Hinrichsen [Hinrichsen, 1992], while Blechschmidt himself mentioned Kircheiss only in the prefaces of some of his books [Blechschmidt, 1960, 1963, 1973].

Kircheiss fulfilled 2 different jobs in Blechschmidt's institute. The job of a chief modeler, responsible for the construction of Blechschmidt's embryo replicas, and the job of a scientific illustrator, responsible for the production of most of the replica-based illustrations that were shown in Blechschmidt's books on human embryology. The modeling of enlarged embryo replicas and the creation of drawings depicting these replicas were fundamental jobs in the traditional research on the anatomy of human embryos. It, therefore, may be no wonder that the names of a few eminent modelers and/or scientific illustrators are well-known among those interested in human embryology. The names of the modelers Adolf Ziegler $\left({ }^{*} 1820-1889 \dagger\right)$ and Friedrich Ziegler $\left({ }^{*} 1860-1936 \dagger\right)$, for example, are intimately related to the scientific work of Wilhelm His and other 19th century embryologists. These embryologists were interested in the production of enlarged wax replicas of human embryos from their collections for the purposes of publication and academic teaching. This was made possible by the collaboration with the studio of Adolf and Friedrich Ziegler [Hopwood, 2002]. The Ziegler studio built wax models of human embryos in collaboration with the embryologists and manufactured copies of these wax models in series and sold them to universities and colleges all over the world. These models were, therefore, associated not only with the names of the embryologists who wanted to publish "their" embryos (e.g., Wilhelm His), but also with the names of the modelers [e.g., "His-Ziegler models" or "His-Osterloh model“; Osterloh, 1929].

Modeling of human embryo replicas also played a fundamental role in the research of the Department of Embryology at the Carnegie Institution in Baltimore, MD, USA, during the first half of the 20th century. Here, the job of the chief modeler was done by Osborne O. Heard $(* 1890-1983 \dagger)$. Heard had studied sculpting and patternmaking at the Maryland Institute of Art and Design. He became an employee of the Carnegie Department of Embryology in 1913 and was working there for 42 years. He invented a modification of Born's wax plate reconstruction method and used the Department's collection of serially sectioned embryos for building of hundreds of moderately enlarged replicas of human embryos or parts/organs of these embryos [Wellner, 2014]. The gross anatomy of human embryos, as depicted by these replicas, was published in the form of drawings made by the Department's scientific illustrators. The most prominent of these illustrators was James F. Didusch $\left({ }^{*} 1890-1955 \dagger\right)$. Didusch studied mechanical drawing and Fine Arts at the Maryland Institute of Art and Design, and medical illustration in the Department of Art as Applied to Medicine at the Johns Hopkins Medical School in Baltimore. He was appointed as an illustrator of the Carnegie Department of Embryology in 1913 and remained there until his death in 1955 [Corner, 1955; Altemus, 1992]. His beautiful drawings of human embryos not only formed the visual basis of many publications from the Carnegie Department of Embryology, but, additionally, became classics of embryological art and were widely copied in textbooks. If we compare the process of model making in 
Fig. 8. a This historical microphotograph, from the recently rediscovered photo archive, shows one section from the complete series of 189 histological sections through the body of embryo "09-04-1954, $3.4 \mathrm{~mm}$ ". b Enlarged prints of the microphotographs, taken from the histological sections, were used to produce a complete series of 189 color-coded contour line drawings.

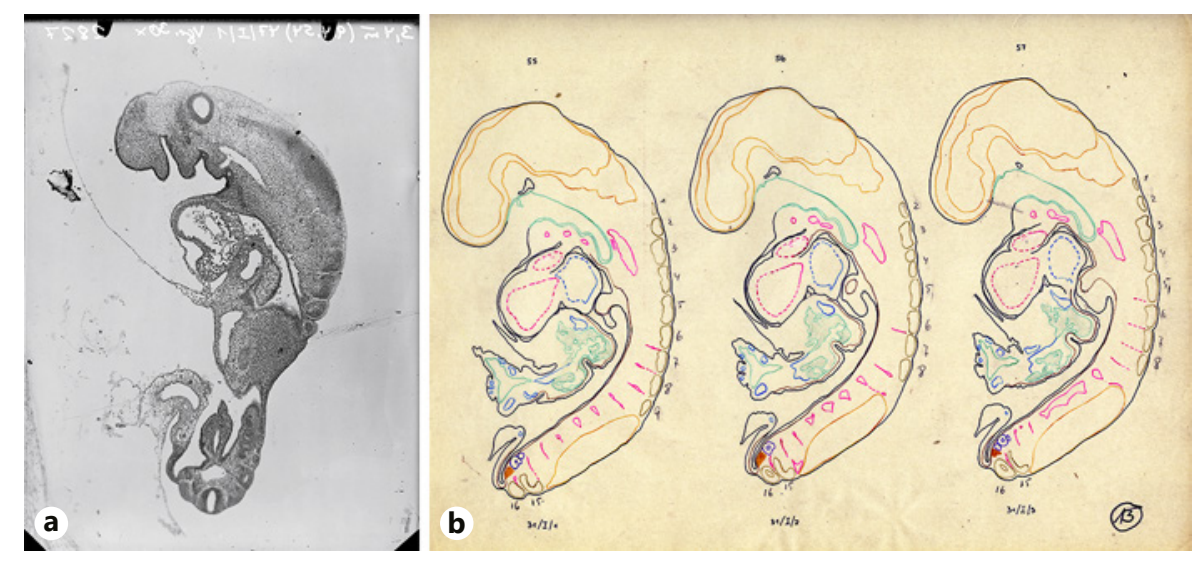

the Carnegie Department of Embryology with the situation in Blechschmidt' institute, we can find several differences between the 2 institutions. In the Carnegie Department of Embryology, the jobs of model making and drawing were performed by 2 different persons (O.O. Heard and J.F. Didusch) and both of them had studied arts and design. Moreover, the contributions of these 2 persons to the Department's scientific work received public recognition, so that their names are well-known among the community of human embryologists. In Blechschmidt's lab, the jobs of a modeler and scientific illustrator were done by the same person (W. Kircheiss), and this person had a technical (engineer) rather than an artistic background. In contrast to Heard and Didusch, Kirchheiss' contribution to Blechschmidt's scientific work did not receive public recognition in the past, so that his name was unknown among the community of human embryologists.

The next photograph from the recently rediscovered photo archive brings us back to the technical aspects of making large embryo replicas. It depicts a histological section of the embryo "09-04-1954, $3.4 \mathrm{~mm}$ " (Fig. 8a). This picture illustrates the first step in the reconstruction process, namely the creation of a complete series of 189 microphotographs from the 189 histological sections through the embryo's body. Enlarged prints of these microphotographs were used to produce a series of 189 color-coded contour-line drawings (magnification factor $\times$ 49.75) on tracing paper (Fig. 8b). These line drawings served as the "original dataset" on which the future construction of all replicas of embryo "09-04-1954, $3.4 \mathrm{~mm}$ " was based. This "original dataset" is still present in the archive of the Anatomical Institute.

Histological sections, as well as copies derived from them, document the internal and external anatomy of serially sectioned biological objects in a purely 2 -dimen- sional fashion. They do not provide an image of the original 3D anatomy of such objects, which has been destroyed by the sectioning process. It is basically possible, however, to reconstruct the original 3D shape of serially sectioned objects based on 2-dimensional datasets. For this purpose, the sections or copies of sections simply must be rearranged in their original spatial order. The first method used for the 3D reconstruction of serially sectioned biological objects was invented by the German anatomist and embryologist Gustav Born [Born, 1876, 1883 ]. Born used wax plates to produce enlarged replicas of histological sections. The outer and inner contours of the object seen on the histological sections were copied on the wax plates at a chosen magnification, and the wax filling the empty spaces between the contour lines was cut away from the plates. The wax plate replicas were stepwise stacked on each other in the original spatial order. The final result was an enlarged 3D replica of the original object (e.g., an embryo) that was made of wax. Corresponding to Born's original reconstruction method, Blechschmidt's method also used wax plates to produce enlarged replicas of histological sections. In contrast to Born's method, however, Blechschmidt used these plates as negative matrices. This means that the wax was cut away from those areas of the wax plate that were destined to form the solid parts of the future $3 \mathrm{D}$ replica. The resulting gaps in the wax plate then were filled with a pasty mixture of a synthetic resin (Leguval K25, Bayer AG, Germany) and calcium sulfate. After the polymerization of the resin, the next wax plate was added to the continuously growing stack of wax plates, and the gaps in this plate were also filled with resin. To make the identification of a given anatomical structure (e.g., blood vessel) within the growing stack of plates easier and to facilitate the identification of every tenth plate, the resin was 
Fig. 9. a, b These historical photographs, from the recently rediscovered photo archive, show the replica of a $6.3 \mathrm{~mm}$ embryo from Blechschmidt's collection ("01-08$1951,6.3 \mathrm{~mm}$ ") at 2 subsequent steps of the reconstruction process: (1) before smoothening of its stepped surfaces (a1, a2), and (2) after smoothening of its stepped surfaces (b1, b2). Note the local differences in staining of the resin, which made it easier to identify, in the "stepped" replica: first, a given anatomical structure and second, every 10 th plate.
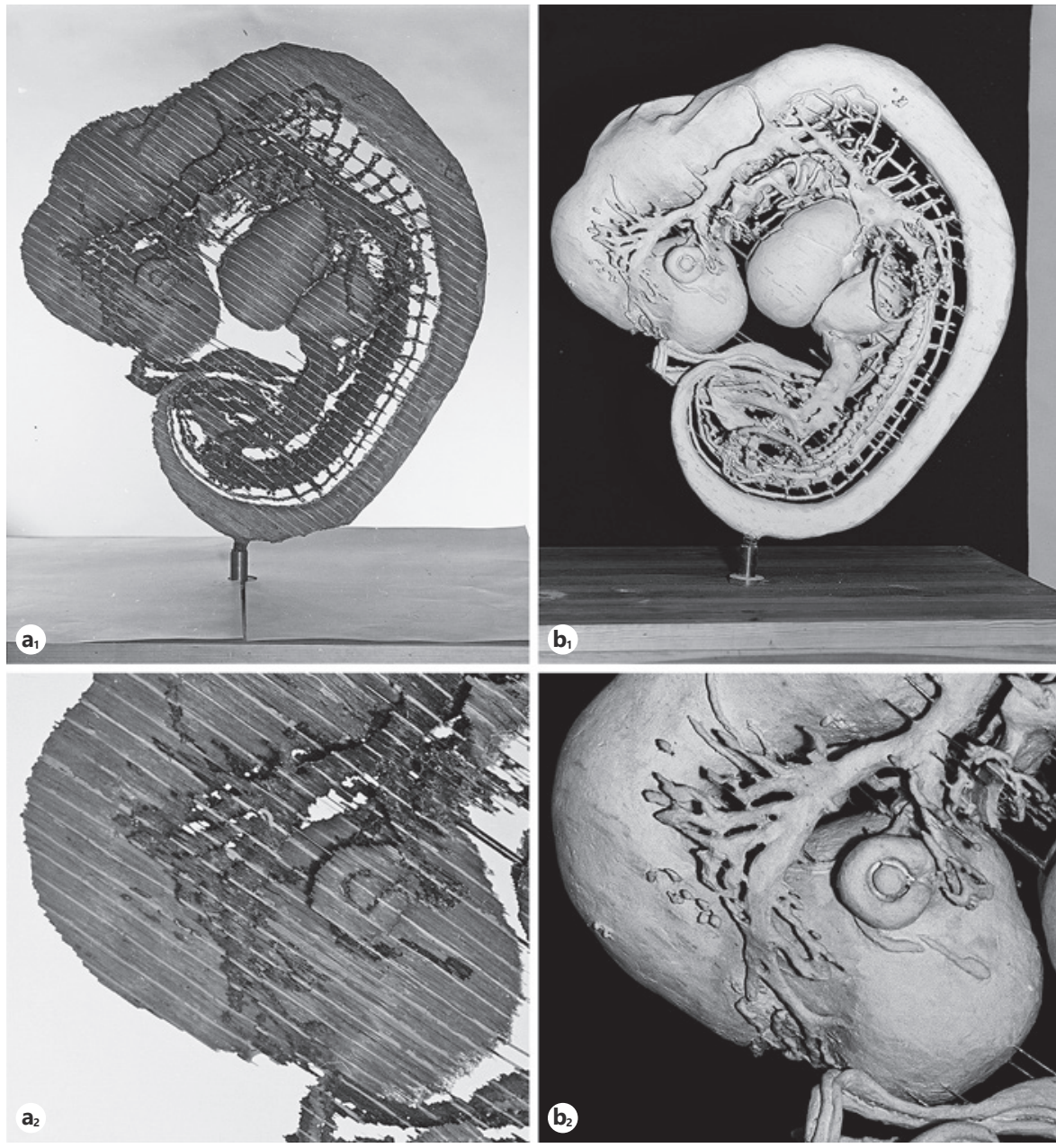

stained with different colors. The abovementioned procedures were continuously repeated until the last wax plate was mounted on the stack and the resin filled in its gaps was polymerized. The wax then was removed from the wax plate stack by usage of a steam jet. This led to the exposure of a 3D replica of the embryo that was made of stacked resin plates and, therefore, had stepped outer and inner surfaces. Blechschmidt's modification of Born's method for constructing enlarged embryo replicas from serial histological sections basically corresponded to the reconstruction method developed and used in the Department of Embryology at the Carnegie Institution [Mall and Meyer, 1921]. Both institutions used the wax plates as negative matrices. In the Carnegie Department of Embryology, however, the gaps in the wax plates were filled with plaster of Paris, while Blechschmidt used the abovementioned synthetic resin. Usage of the latter filler material allowed the construction of embryo replicas that were of much larger size than those constructed from plaster. The replicas from the Blechschmidt Collection of Human Embryos, therefore, are much larger than those from the Carnegie Collection. A further difference between the replicas from the 2 collections is the condition of their surfaces. The replicas from the Carnegie Collection usually have stepped surfaces, for examples see Fig. 2 in Morgan [2004], and Figures 1 and 10c in Yamada et al. [2015]. This condition reflects the technical reconstruction process and, therefore, gives the replicas the character of constructed rather than biological objects. In Blechschmidt's lab, however, the stepped surfaces of the embryo replica were always smoothened using a grinding machine and resin filler (Dinova, Didier-Werke, Oberlahnstein, Germany). This procedure removed these traces of the technical reconstruction process and gave the replicas the character of biological objects. The smoothened surfaces of the various anatomical structures finally were painted 
according to a color code resembling the color code used in anatomical textbooks and atlases (e.g., yellow $=$ nervous system; red = arteries; blue = veins).

The abovementioned differences between the replicas from the Carnegie Collection and those from the Blechschmidt Collection can be explained by an institutionspecific difference in usage of the replicas. The plaster replicas from the Carnegie Collection were exclusively used for research purposes. They were not built for any public exhibition and, therefore, had a moderate size and retained their stepped surfaces. The moderately enlarged replicas enabled scientists to study the gross anatomy of the original human embryo specimen with the naked eye. The documentation and publication of the observations then were made in the form of drawings, which depicted the replicas with smooth instead of stepped surfaces. Thus, in the Carnegie Department of Embryology, the process of smoothening of the stepped surfaces of the embryo replicas occurred exclusively in the mind of the scientific illustrator (mostly James F. Didusch) during the production of the illustrations that were destined for publication. Blechschmidt's replicas of human embryos, on the other hand, were built not only for research purposes. They chiefly form parts of his replica collection of human embryos, which, in its entirety, serves as a single model for early human morphogenesis. This multi-part model, which is shown in a dedicated exhibition hall at the Göttingen Anatomical Institute, was chiefly built up for teaching medical students and young doctors. It is, therefore, no wonder that Blechschmidt's embryo replicas have an exceptionally large size and that these replicas have smooth ("biological") surfaces.

In the recently rediscovered photo archive, we have found a few pictures illustrating Blechschmidt's reconstruction method. These photographs depict embryo replicas at 3 subsequent steps of the reconstruction process: (1) before smoothening of their stepped surfaces, (2) after smoothening of their surfaces, and (3) after painting of the smoothened surfaces. Among these pictures, we, unfortunately, did not find any photograph showing replicas from embryo "09-04-1954, $3.4 \mathrm{~mm}$ " in a nonsmoothened or smoothened but nonpainted condition. The reconstruction process of Blechschmidt's embryo replicas, therefore, is illustrated here by 2 pictures showing the replica of a $6.3 \mathrm{~mm}$ embryo ("01-08-1951, $6.3 \mathrm{~mm}$ ") before smoothening of its stepped surfaces (Fig. 9a1, a2) and after smoothening of its surfaces (Fig. 9b1, b2). Not visible on any of the historical photographs are the countless metal rods and wires that were placed in the polymerizing resin to stabilize parts of the embryo replica that needed

Biography of a Historical $3.4 \mathrm{~mm}$ Human

Embryo Specimen

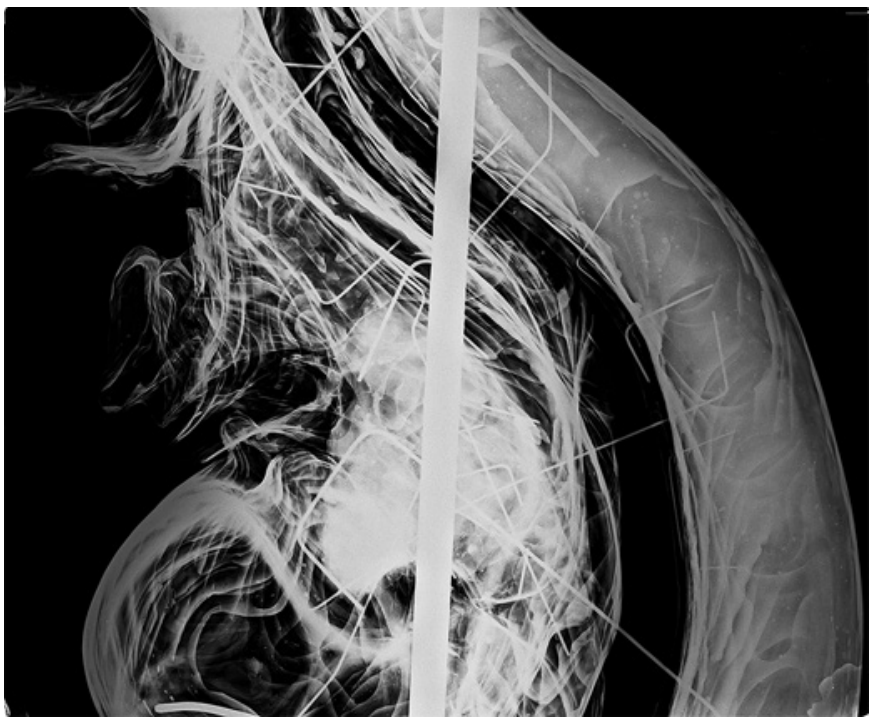

Fig. 10. This X-ray image, taken from one replica from Blechschmidt's collection, depicts the inner structures (metal rods and wires) that were integrated into the growing stack of wax/resin plates for mechanical stabilization of the embryo replica after finishing of the reconstruction process.

additional mechanical support and might have fallen off after removal of the wax. They recently were made visible using X-ray imaging (Fig. 10) as part of a conservation science project evaluating the material conditions of these objects from the very beginning of the plastic age [Krieg, 2019].

Regarding embryo "09-04-1954, $3.4 \mathrm{~mm}$ ", we have found a few historical photographs showing 2 of the 3 abovementioned replicas at the end of the reconstruction process (Fig. 11a1-2, b1-b2). Comparing these historical photographs with reproductions of drawings showing the replicas suggests that the former (Fig. 11a2, b2) were used for the production of the latter (Fig. 11a3, b3). The production of drawings showing the external and internal anatomy of embryo "09-04-1954, $3.4 \mathrm{~mm}$ ", thus, may be regarded as the last step in the process of transformation of this embryo from an individual biological object, hidden in its mother's womb, into a set of visible scientific documents (photographs, serial histological sections, 3D replicas, drawings, etc.) during the Blechschmidt era. We have noted, however, that on the historical photographs, the replicas have glossy surfaces. This contrasts to the today's situation, where the replicas have a matt finish (see Fig. 6). Thus, the today's coloration of the replicas obviously does not represent the original situation. We do not know the reasons for changing the painting of the replicas nor do we know the exact 
time point when the change happened. The replica collection moved to the new building of the Anatomical Institute in 1964. On photographs from this year, the replicas of Blechschmidt's collection have a matt finish (Fig. 12). This indicates that the change in painting of the replicas must have happened before or during 1964.
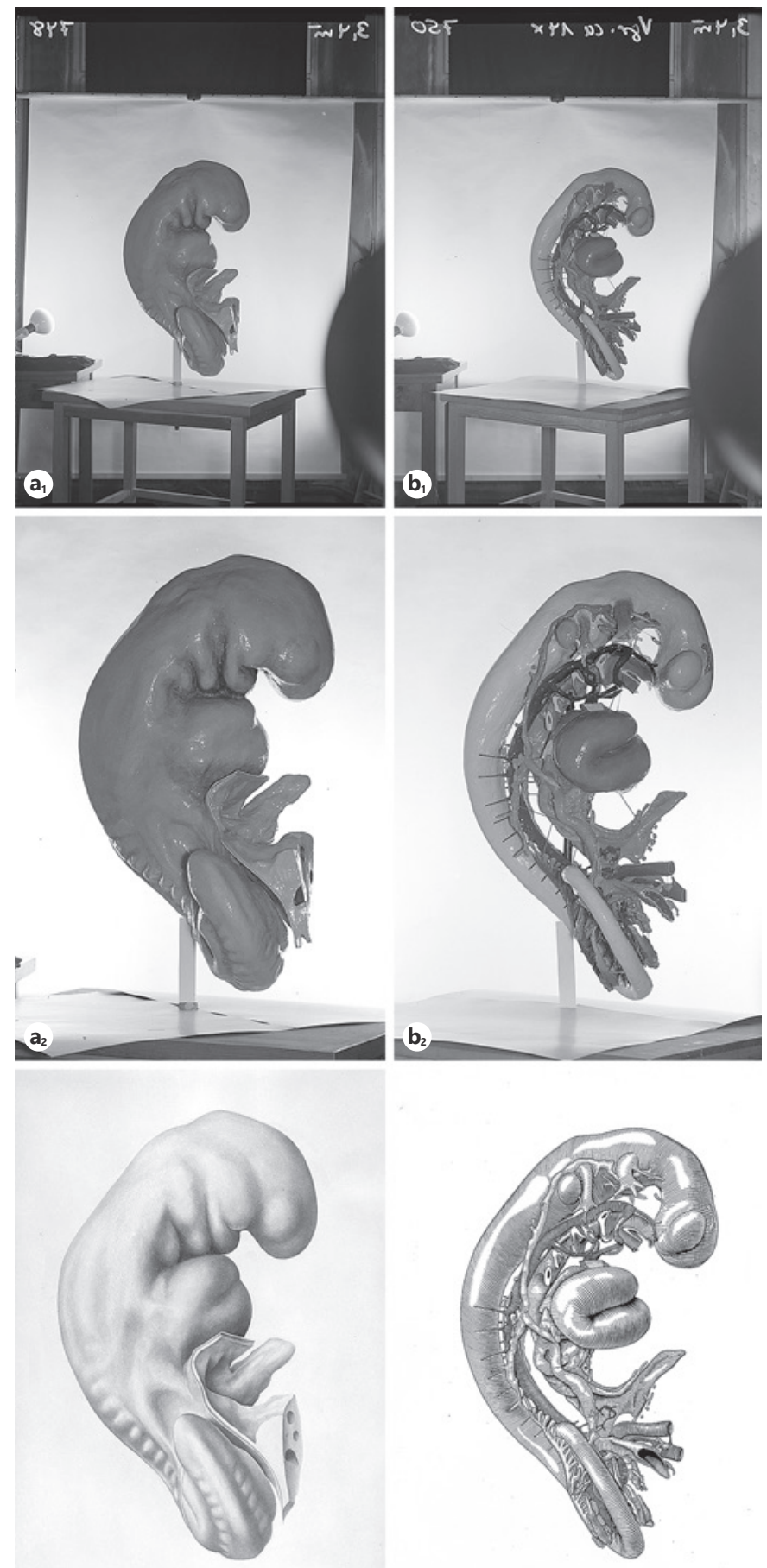

$\mathbf{a}_{3}$

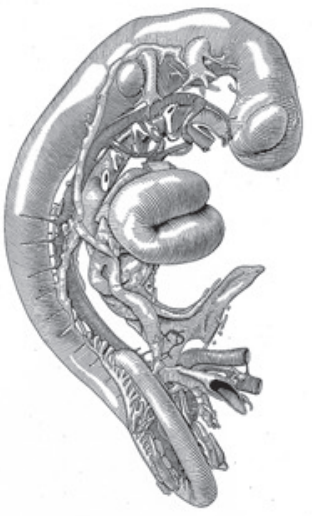

$b_{3}$

\section{Did Blechschmidt Use Embryo “09-04-1954, 3.4 mm" for Specific Scientific Projects?}

In the abovementioned letter of thanks, Blechschmidt wrote back to the sender of embryo "09-04-1954, $3.4 \mathrm{~mm}$ " that he had been looking for an embryo of the appropriate size for a long time (years), since such an embryo would make it possible for him to study the movement of the developing diaphragm during critical stages of development ("Ich suche seit J. genau einen Embryo dieser Größe um endlich die Entwicklungsbewegungen des Zwerchfells in den kritischen Stadien untersuchen zu können"). In view of this statement, the question may arise whether the study of this embryo had allowed Blechschmidt to deduce the "movement" of the diaphragm he was looking for. A thorough review of Blechschmidt's publications did not provide any evidence that he had used this embryo specifically for such a project. In his 1960 book on the stages of human development before birth, for example, he illustrated the spatial displacement of the developing diaphragm by line drawings of human embryos of $4.2 \mathrm{~mm}, 10 \mathrm{~mm}$, and $29 \mathrm{~mm}$ crownrump length [see Fig. 455-457 on page 519 in Blechschmidt, 1960]. Our analyzes of the rediscovered photo archive and of the publications from Blechschmidt's lab have disclosed that; for answering specific scientific questions (e.g., morphogenesis of the pharyngeal arch arteries), Blechschmidt usually did not build replicas of whole embryos. Instead, he built embryo replicas that depicted only parts of the body (regions of interest). Among the photographs from the recently rediscovered photo archive, we have found 2 pictures from a hitherto unknown replica of embryo "09-04-1954, 3.4 $\mathrm{mm}$ " that depicts only the caudal (subdiaphragmatic) body half with a special focus on the topographical relationships of the developing hindgut, umbilical vessels, and urogenital system (Fig. 13). This suggests that Blechschmidt might have used the embryo "09-04-1954, $3.4 \mathrm{~mm}$ " in an unpublished project on the topogenesis of the urogenital system.

Fig. 11. a, b These historical photographs, from the recently rediscovered photo archive, show 2 replicas of the embryo "09-04-1954, $3.4 \mathrm{~mm}$ " in right lateral views at the end of the construction process. These replicas are the same as those shown in Fig. 6 a1, c1. The views depicted in the historical photographs correspond to views depicted in drawings from Blechschmidt's lab (photographical reproductions found in the rediscovered photo archive). This suggests that the former $(\mathbf{a} 2, \mathbf{b} 2)$ were used to produce the latter (a3, b3). For better comparison between the photographs and the drawings, the photographs of the replicas are shown at low $(\mathbf{a} \mathbf{1}, \mathbf{b} \mathbf{1})$ and high (a2, b2) magnifications. Note that on these historical photographs, the replicas have glossy surfaces. This contrasts to the today's situation, where the replicas have a matt finish (see Fig. 6). 


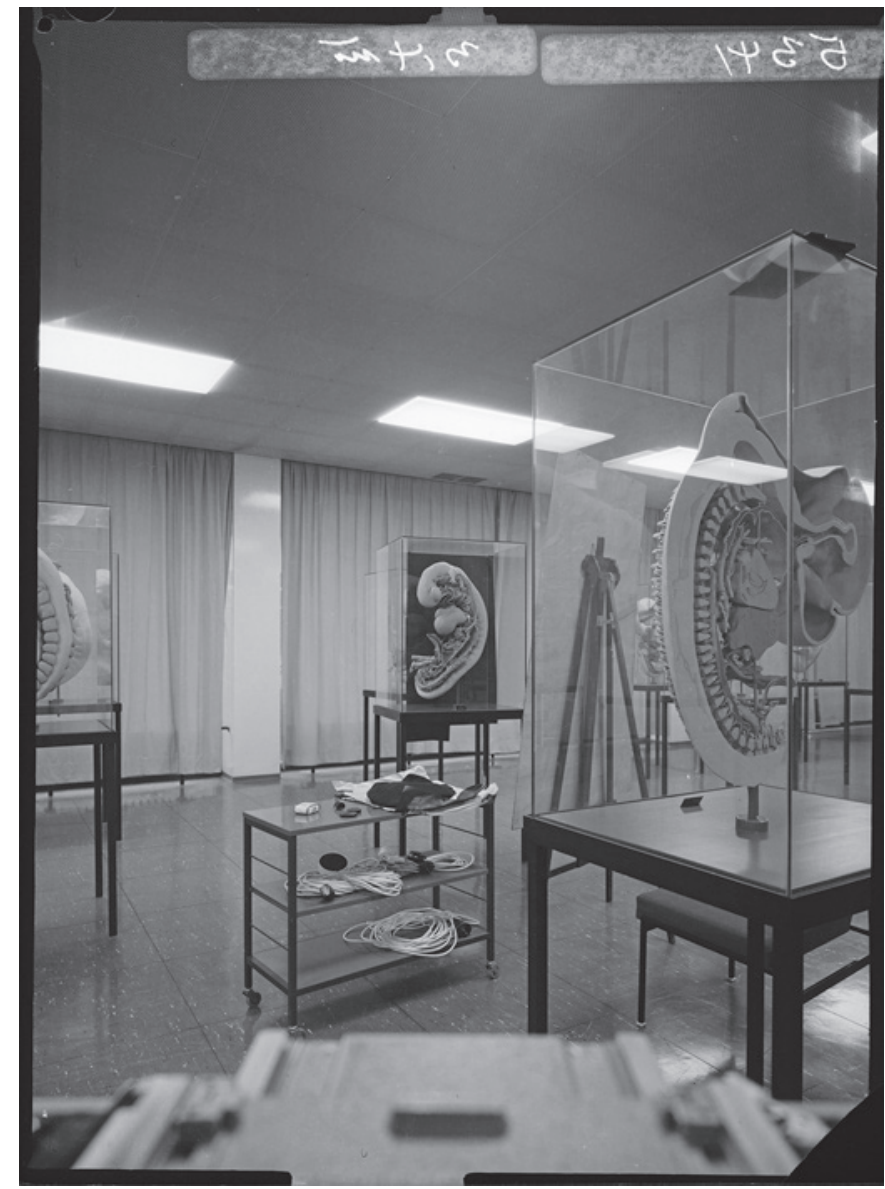

Fig. 12. This historical photograph, from the recently rediscovered photo archive, show one replica of the embryo "09-04-1954, 3.4 $\mathrm{mm}$ " during installation of the replica collection in the exhibition hall at the new building of the Anatomical Institute in 1964. Note that the surfaces of the replicas have a matt finish.

\section{What Is the Current and Future Value of the Historical Blechschmidt Collection of 3D Replicas of Human Embryo?}

For more than 100 years, the complex 3D anatomy of very small biological objects, such as human embryos, could be visualized and analyzed only with the aid of enlarged physical replicas that were reconstructed from serial histological sections of the specimens by modifications of Born's wax plate method. As described in the preceding paragraphs, this procedure was time-consuming and bound many resources of those institutions performing research on the anatomy of human embryos. It is, therefore, no wonder that when the focus of embryological research changed from descriptive morphology to ex-
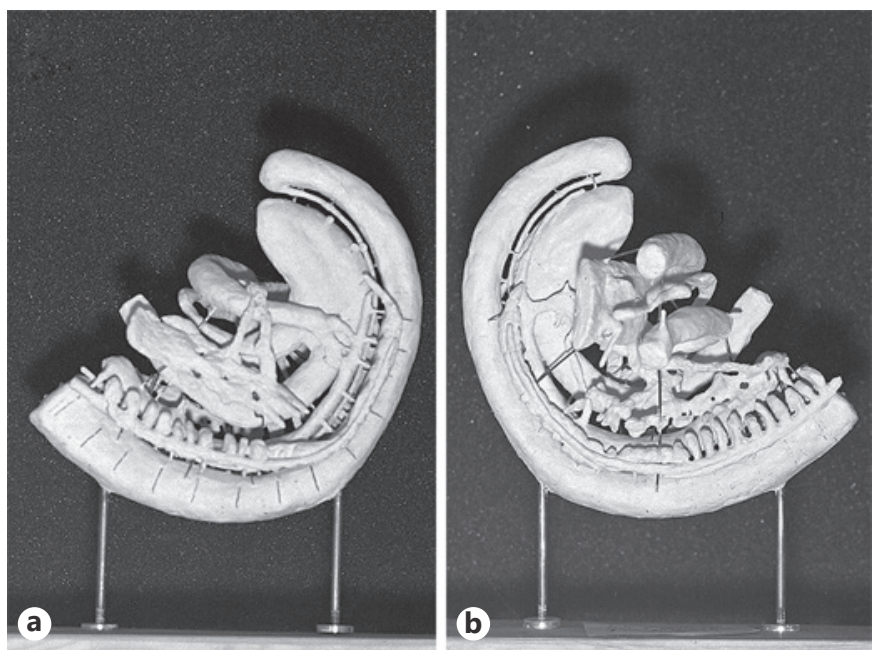

Fig. 13. a, b These historical photographs, from the recently rediscovered photo archive, show an unknown replica of embryo "0904-1954, $3.4 \mathrm{~mm}$ " that depicts anatomical structures of only the subdiaphragmatic body half. a Left lateral view. b Right lateral view.

perimental embryology, developmental physiology and genetics, the activity of physical model-making ceased in many departments of embryology all over the world during the 1940s and 1950s. Descriptive studies on the anatomy of human embryos were out of date for a long time, and there was a tendency to see physical replicas or models of human embryos as a kind of old-fashioned museum objects. It is, therefore, no wonder that Blechschmidt's collection of human embryo replicas sometimes is named the "Blechschmidt Museum."

During the past 20 years, however, there was a rebirth in the interest in the dynamically changing anatomy of human embryos. Thanks to diverse computer-based imaging techniques, it is now possible to visualize and analyze the 3D anatomy of serially sectioned as well as intact, chemically preserved embryos on virtual replicas displayed on the monitor of a PC [Yamada et al., 2010]. Projects have started to make digital copies of the histological sections from human embryos stored in historical collections of human embryos, such as the Carnegie Collection in the United States [Gasser et al., 2014; De Bakker et al., 2016], the Kyoto Collection in Japan [Takakuwa, 2018], and also the Blechschmidt Collection in Germany [Miyazaki et al., 2018], and to make these digital datasets webaccessible for research purposes. The digitized histological sections from human embryos can be used for the construction of virtual 3D replicas via virtual stacking of the sections, and such replicas have been used for creating an 
interactive 3D digital atlas of human development spanning the first 2 months of human prenatal life [De Bakker et al., 2016]. This atlas has proven to significantly improve students' understanding of the dynamically changing anatomy of human embryos [Chekrouni et al., 2020].

In view of the abovementioned facts, the question arises as to whether physical embryo replicas, such as those shown in the historical Blechschmidt Collection, may still have an impact on the understanding of the complex 3D anatomy of human embryos in the current era of digital visualization of complex anatomical situations. In order to find an answer to this question, we should first note that it is not only human embryology that has seen a rebirth during the past few years. It is also the usage of physical 3D replicas/models in medicine. The latter rebirth is based on 3D printing, which is a technology that uses 3D digital data sets for producing physical 3D replicas [Rengier et al., 2010]. 3D printing facilitates the production of anatomical models/replicas for medical education and training at relatively low costs and in short times [Garcia et al., 2018]. Thus, at the present time, we can use 2 different kinds of computer-based 3D replicas/models for understanding the complex anatomy of human beings: (1) virtual 3D replicas and (2) physical 3D replicas. The efficiency of the usage of physical versus virtual 3D replicas in understanding of complex anatomical situations has been compared in only a few studies. Such studies suggest that physical replicas are more effective in under- standing complex 3D anatomy than virtual replicas [Khot et al., 2013; Preece et al., 2013; Huang et al., 2018; Cai et al., 2020]. In view of these findings, we think that the usage of physical replicas, such as those produced from embryo "09-04-1954, $3.4 \mathrm{~mm}$ ", has a future in teaching as well as in research on the anatomy of human embryos.

\section{Statement of Ethics}

The human embryo specimen discussed in this article was obtained prior to regulations related to informed consent in Germany. Ethical issues related to the Blechschmidt Collection of human embryos are discussed in detail in Markert [2019, 2020].

\section{Conflict of Interest Statement}

There is no conflict of interests.

\section{Funding Sources}

This work did not receive external funding.

\section{Author Contributions}

Both authors (J.M., M.M.) collected and analyzed the data, wrote the manuscript, and prepared the figures.

\section{References}

Altemus AR. The life and work of James F. Didusch. J Biocommun 1992;19:8-21.

Blechschmidt E. Über die Wachstumsdynamik der Gewebe im menschlichen Körper (Der Ausdruck der Wachstumsmechanik in der Körperform). Göttingen: Universität Göttingen; 1944.

Blechschmidt E. Reconstruction method by using synthetic substances; a process for investigation and demonstration of developmental movements (in German). Z Anat Entwicklgesch. 1954;118(2):170-4.

Blechschmidt E. Embryological studies from the functional point of view (in German). Acta Anat (Basel). 1955;24(3区4):339-92.

Blechschmidt E. Die vorgeburtlichen Entwicklungsstadien des Menschen / The stages of human development before birth. Basel: Karger; 1960.

Blechschmidt E. Der menschliche Embryo. Stuttgart: Schattauer; 1963.

Blechschmidt E. Die pränatalen Organsysteme des Menschen. Stuttgart: Hippokrates; 1973.
Born G. Über die Nasenhöhlen und den Tränennasengang der Amphibien. Morphol JB. 1876; 2:578-80.

Born G. Die Plattenmodellirmethode. Archiv f mikrosk Anatomie. 1883;22(1):584-99.

Born M, Brandt W, Born G. In memoriam Gustav Born, experimental embryologist. Acta Anat (Basel). 1950;10:466-75.

Cai S, He Y, Cui H, Zhou X, Zhou D, Wang F, et al. Effectiveness of three-dimensional printed and virtual reality models in learning the morphology of craniovertebral junction deformities: a multicentre, randomised controlled study. BMJ Open. 2020;10:e036853.

Chekrouni N, Kleipool RP, de Bakker BS. The impact of using three-dimensional digital models of human embryos in the biomedical curriculum. Ann Anat. 2020;227:151430.

Corner GW. Mr. J.F. Didusch. Nature. 1955;175: 750.
De Bakker BS, De Jong KH, Hagoort J, de Bree K, Besselink CT, de Kanter FE, et al. An interactive three-dimensional digital atlas and quantitative database of human development. Science. 2016;354:aag0053.

Eternod ACF. Sur un ouf human de $16,3 \mathrm{~mm}$ avec embryon de 2,1 $\mathrm{mm}$ (uterus et adnexes). Soc Helvet Sci Natur. 1896;79:164-9.

Garcia J, Yang Z, Mongrain R, Leask RL, Lachapelle K. 3D printing materials and their use in medical education: a review of current technology and trends for the future. BMJ Simul Technol Enhanc Learn. 2018;4:27-40.

Gasser RF, Cork RJ, Stillwell BJ, McWilliams DT. Rebirth of human embryology. Dev Dyn. 2014;243:621-8.

Hinrichsen KV. In memory of the anatomist and embryologist Erich Blechschmidt (19041992) (in German). Ann Anat - Anatomischer Anzeiger. 1992;174(6):479-84.

Hopwood N. A company of wax homunculi. In: Hopwood N. Embryos in wax. Models from the Ziegler studio. Cambridge: Cambridge University Press; 2002. p. 69-75. 
Huang Z, Song W, Zhang Y, Zhang Q, Zhou D, Zhou X, et al. Three-dimensional printing model improves morphological understanding in acetabular fracture learning: A multicenter, randomized, controlled study. PLoS One. 2018;13:e0191328.

Khot Z, Quinlan K, Norman GR, Wainman B. The relative effectiveness of computer-based and traditional resources for education in anatomy. Anat Sci Educ. 2013;6:211-5.

Krieg P. Die humanembryologischen Repliken aus der Blechschmidt-Sammlung des Zentrums Anatomie der Universität Göttingen. Naturwissenschaftliche Untersuchungen und konservatorische Annäherung. Erfurt: Fachhochschule Erfurt Master Thesis; 2019.

Mall FP, Meyer AW. Studies on abortuses: a survey of pathologic ova in the Carnegie Embryological Collection. Carnegie Inst Wash Publ. 1921;275(12):1-364.

Männer J. Die humanembryologische Dokumentationssammlung Blechschmidt. Eine modellbasierte Gesamtschau auf einen dynamischen Formbildungsprozess. In: Ludwig D, Weber C, Zauzig O, editors. Das materielle Modell. Objektgeschichten aus der wissenschaftlichen Praxis. München: Wilhelm Fink; 2014. p. 33-9.
Markert M. Die Humanembryologische Dokumentationssammlung Blechschmidt: Geschichte einer sensiblen Sammlung, 19391973. Ergebnisse und Empfehlungen des Provenienzforschungsprojektes. Göttingen: GoeScholar; 2019.

Markert M. Ethical Aspects of Human Embryo Collections: A Historically Grounded Approach to the Blechschmidt Collection at the University of Göttingen. Cells Tissues Organs. 2020;209:189-99.

Miyazaki R, Makishima H, Männer J, Sydow HG, Uwabe C, Takakuwa T, et al. Blechschmidt Collection: re-visiting specimens from a historical collection of serially sectioned human embryos and fetuses using modern imaging techniques. Congenit Anom (Kyoto). 2018; 58:152-7.

Morgan LM. A social biography of Carnegie embryo no. 836. Anat Rec B New Anat. 2004;276: 3-7.

Müller F, O'Rahilly R. Wilhem His and 100 years of human embryology (in German). Acta Anat (Basel). 1986;125:73-5.

O'Rahilly R, Müller F. Developmental stages in Human embryos, including a revision of Streeter's , horizons' and a survey of the Carnegie collection. Washington: Carnegie Institution of Washington; 1987.

Osterloh P. Modelle der Anatomie, Zoologie, Botanik und Landwirtschaft. Leipzig: Selbstverlag; 1929.
Preece D, Williams SB, Lam R, Weller R. “Let's get physical". Advantages of a physical model over 3D computer models and textbooks in learning anatomy. Anat Sci Educ. 2013;6: 216-24.

Rengier F, Mehndiratta A, von Tengg-Kobligk H, Zechmann CM, Unterhinninghofen R, Kauczor $\mathrm{HU}$, et al. 3D printing based on imaging data: review of medical applications. Int $\mathrm{J}$ Comput Assist Radiol Surg. 2010;5:335-41.

Takakuwa T. 3D analysis of human embryos and fetuses using digitized datasets from the Kyoto Collection. Anat Rec (Hoboken). 2018 301(6):960-9.

Wellner BS. Osborne Overton Heard (18901983). Embryo Project Encyclopedia (201006-28); 2014. Available from: http://embryo. asu.edu/pages/osborne-overton-heard (18.02.2014)

Yamada S, Samtani RR, Lee ES, Lockett E, Uwabe C, Shiota K, et al. Developmental atlas of the early first trimester human embryo. Dev Dyn. 2010;239:1585-95.

Yamada S, Hill M, Takakuwa T. Human embryology. In: New Discoveries in Embryology. IntechOpen; 2015. Available from: https:// www.intechopen.com/books/new-discoveries-in-embryology/human embryology. 